\title{
Ethical Decision Making in Academic Dishonesty with Application of Modified Theory of Planned Behavior: A Review
}

\author{
Chan Ling Meng ${ }^{1,2}$, Jamilah Othman ${ }^{3}$, Jeffrey Lawrence D'Silva ${ }^{3} \&$ Zoharah Omar $^{1}$ \\ ${ }^{1}$ Faculty of Educational Studies, Universiti Putra Malaysia, Malaysia \\ ${ }^{2}$ Faculty of Business and Finance, Universiti Tunku Abdul Rahman, Malaysia \\ ${ }^{3}$ Institute for Social Science Studies, Universiti Putra Malaysia, Malaysia \\ Correspondence: Chan Ling Meng, Faculty of Business and Finance, Universiti Tunku Abdul Rahman (Perak \\ Campus), Jalan University, Bandar Barat, 31900 Kampar Perak, Malaysia. Tel: 901-2928-6382. E-mail: \\ chanlm@utar.edu.my
}

$\begin{array}{lr}\text { Received: January 16, } 2014 & \text { Accepted: February 19, } 2014 \quad \text { Online Published: February } 26,2014 \\ \text { doi:10.5539/ies.v7n3p126 } & \text { URL: http://dx.doi.org/10.5539/ies.v7n3p126 }\end{array}$

\begin{abstract}
This conceptual paper studies the application of the Theory of Planned Behavior (TBP) in academic dishonesty with the mediating variable of ethical ideologies. The study reviews literature on the Theory of Planned Behavior and past studies pertaining to academic dishonesty. The paper analyses the relationship of the variables of TPB on academic dishonesty with ethical ideologies. A conceptual research framework is presented; it provides insight into predicting and understanding how academic dishonesty can occur. The framework suggests that ethical ideology is significantly strengthened by the application of TPB in understanding and predicting how academic dishonesty occurs. Given that ethical ideology provides guidance in judging right and wrong, duty, obligation and moral responsibility, it is an appropriate tool for the researcher, who needs better understanding to diagnose the influences of ethical ideology on unethical behaviour.
\end{abstract}

Keywords: ethical dilemma, university students, dishonesty, leadership

\section{Introduction}

Recent years have seen a series of high profile scandals and corporate collapses. Enron, Global Crossing and Adelphia Comm. filed for bankruptcy after fraud was disclosed. The dishonest behaviour of managers has caused their organisations' stock prices to fall dramatically (Wang \& Kleiner, 2005). Due to such unethical actions carried out by the companies, public start losing their trust towards the companies. Farnsworth and Kleiner (2003) suggested that components of leadership, ethics, and responsibility are crucially acquired in business today as it is suffering from ethical naïveté.

Previous studies (McCall, 1988; Nonis \& Swift, 2001; Sims \& Sims, 1991; Stone et al., 2009), strongly indicates that people who behave unethically at school are most likely to engage in unethical behaviour at their workplace. Academic dishonesty has been found to correlate with fraudulent financial activity (Chan \& Leung, 2006; Chen $\&$ Tang, 2006). Thus, it is important to understand the attitudes and intentions of undergraduates faced with ethical dilemma (Petress, 2003).

Stone et al. (2009) suggested that academic dishonesty is a likely antecedent to engaging in dishonorable behavior at work. It may endanger employees' career advancement and causes the companies face the risks of violation. Furthermore, McCall (1988) found that dishonorable behavior and being too ambitious or playing politics are significantly related to academic dishonesty. Smyth and Davis (2004) acknowledged that students are unenlightened of the guidelines of academic integrity, and even they do aware of it, they still overweight their personal gain than the moral values (Ahmad et al., 2008). Ahmad et al.'s (2008) findings indicated that students perceived such unethical action as companionably acceptable in accordance with previous studies such as Grimes (2004), Smyth and Davis (2004), etc. These indications significantly suggest that students, our future managers, are less likely to be aware of the importance of academic integrity.

Besides that, in the study of Arieff et al. (2008), it showed that awareness of students towards academic cheating still in infant stage, where they believe that academic cheating is okay practice as everyone is doing. Hence, this paper urges to improve the awareness among academicians and students towards the academic cheating and 
enhance the academic integrity in the university.

Today, as technology imbues every part of our daily routine, the ethical behavior of professionals is more salient than ever. Hence, it is important to ensure that graduates are more sensible toward their ethical and professional duty. Shaw (2008) suggested that ethics begins with each individual, with their inner feelings, which subsequently translate into ethical behaviour. Individuals learn to adapt ethical principles through their socialisation process, life experiences and critical reflection, together with the explicit and implicit standard of culture. Hence, ethical values have been widely recognised as a crucial element in education systems. It is the desire of every university to put in good morality students as well as to develop an honest culture among undergraduates. It is the accountability of the university to chandelle with more productive ways to persuade the students and the importance of academic integrity and expeditiously responding to acts of academic dishonesty.

Given the high rates of academic dishonesty, such as cheating, plagiarism, etc, it would seem that current education approaches seems to have little effect on behavior. As such, teaching approaches have been inadequate in dealing the moral development of undergraduates (Harding et al, 2007). Hence, the justification of this paper is to propose an understanding of the underlying reason academic dishonesty and to decide the most effective ways for controlling such behaviors with the application TPB, as it has shown remarkable ability to foresee and provide a principle for academic dishonesty (Ajzen, 1991; Passow et al., 2006; Stone et al., 2010).

The aim of this article is to review the previous studies on the employment of the original Theory of Planned Behavior and its modified versions in the context of academic integrity, specifically with the mediating variable of ethical ideology (Forsyth, 1980). First, the authors will review the literature pertaining to academic dishonesty, followed by a review on the model of TPB (Ajzen, 1991) and ethical ideology (Forsyth, 1980) and a discussion on the coherency between the variables. It followed by the development of the proposition of this study. Third, the construction of the proposed research framework will be described. Lastly, the paper concludes with the new insight proposed from the conceptual work and their implications.

\section{Literature Review and Propositions}

\subsection{Academic Dishonesty}

Symaco and Marceb (2003) defined academic dishonesty as a contravention of rules and regulations among most tertiary education institutions. They suggested that academic dishonesty is a serious disorder that has successfully loose a lasting solution no matter how hard or how much effort the institutional to eradicate it. Furthermore, they also argued that nowadays students perceive academic dishonesty as a norm that is common practice among their peers. It is orderly with the study by Finn and Frone (2004), in which they defined academic dishonesty as the violation of enfranchised rules or standard requirement for completion of school homeworks and examination. Such violation included cheating in examination, plagiarising, free-riding and copying assignments. People nauseate it, yet most have compromised it once or several time in their academic study life.

Petress (2003) noted there are many forms of academic dishonesty, ranging from copying test answers from friends, taking an exam on behalf of friends, failure to cite other people's work, taking exams home, faking research papers and pretending they are one's own work, breaking into the exam office or lecturers' files to access the tests or answer keys, sabotaging peers' work or gaining illegal access to school computers to change official grades. Moreover, Roberts (2002) alleged that plagiarism is another form of academic dishonesty whereby authors tend to manipulate the information in favor of what they want to gain.

Gehring and Pavela (1994) define academic dishonesty as an designed action of fraud, in which students seek to argue accreditation for their work or efforts of another without authorisation, or use unauthorized materials or false information in academic exercises or forge academic assignments, intentionally detrimental the assignments of others and helping other students in dishonesty action, such as giving or receiving unauthorized help in an academic exercise or receiving credit for another's work.

Staats et al. (2009) pointed out that academic dishonesty is a type of deviant behavior and it will impact harmful on development of character, hurt others and jeopardize the academic integrity of the particular institution. Students who engage in such deviant behavior place their individual benefit over that of others and put the university's integrity at risk. Dichtl (2003) suggested that academic dishonesty is from peers learning and this unethical behavior establishes a culture where those honesty students feel at disadvantage. Passow et al. (2006) proposed that academic dishonesty undermines the credibility of learning. Lecturers fail to evaluate what the students do not understand if cheating occurs among them. Moreover, it also makes it more difficult for the lecturers to regulate their approaches as they will make wild guess that students are all doing well, which it may 
not be true. This may causes the lecturers fail to acknowledge and recognise the acceptance of knowledge towards their study. Moreover, it also creates difficulties for academics in terms of grading their students.

Roberts (2002) suggested that students tend to engage in this unethical behavior because of: time constraints, uncaring instructors, laziness, peer pressure, poor role model, fear of failure, and technology advancement which allow it to be done with ease. Nowadays, students are more materialistic, money minder, are idle and egotistical (Farnsworth \& Kleiner, 2003). McCabe et al. (2006) suggest reasons students engage in such dishonesty behavior for various of reasons, including their lazy mentality, influences of scholarship and their peer competitions. Ahmad et al. (2008) also suggest that the competitiveness pressure has created uncomfortable attitudes and maybe, that resulted has shown that dishonesty pays. It is consistent with the findings of Chapman and Lupton (2004), that students are aware of cheating is and that even though they know is morally incorrect, but still they continue to cheat as they predict that the gains are outweigh the potential harms, and they treat cheating as normal as others.

Academic dishonesty brings hurts the students and constraint the lecturers from sharing the important knowledge in the learning process. Academic dishonesty challenges the university to place full commitment in order to maintain positive climate to sustain the academic integrity. Farnsworth and Kleiner (2003) observed that the decreasing of moral standards with deviant behaviors in universities has increased the anxiety and worries of the public. Academic dishonesty is especially common in business based programs; students are participating in dishonesty in their study life, and hence it has become a habit for most students. This trend is alarming in the light of empirical evidence of associations between academic dishonesty and both relationship and engagement in unethical workplace behaviour.

Hence, academic dishonesty can be interpreted as defilement of course rules which could damage the academic work of others or assist others in unethical acts, such as cheating, copying answers from others, plagiarism, sabotaging peers' work, free-riding, other fraudulent acts, etc.

\subsection{Theory of Planned Behavior}

Academic dishonesty is the result of rational choice under the volitional control of the individual. Such unethical behavior is anticipated and can be explain through statistical modeling. Ajzen's Theory of Planned Behavior (TPB) has been shown to explain remarkable amounts of changeability, in measures of students' academic dishonesty. Previous studies (Beck \& Ajzen, 1991; Passow et al., 2006) found that TPB shows accurancy in predicting and providing one rationale for academic misconduct. TPB stipulates that three components predict intention to engage in a specific behaviour and intention predicts subsequent engagement in that behaviour, as illustrated in Figure 1. Intention to engage in behaviour is affected by: (1) attitudes toward the behaviour (the beliefs about a specific behaviour and its consequences); (2) subjective norm (the normative expectations of other people who are important to the actor regarding the behaviour); (3) perceived behavioural control (the perceived difficulty or ease of performing the behaviour).

Stone et al. (2009) acknowledged that three components (attitude, subjective norms and perceived behavioral control) work differently to determine intention to perform some behavior. In this theory, intention serves as the immediate antecedent to behaviour. Favourable attitude and supportive group values result in remarkable intention to carry out the behavior. Perceived behavioural control and the perceived ease or difficulty of executing the behaviour, however, can influence both level of intention and the relationship between intention and behaviour. Such as, James may have a favourable attitude toward cheating during his final exam and his peers may also engage in cheating, but the level of examination observation in the exam venue may make cheating impossible.

Ajzen (1991) showed that individuals make rational decisions to engage in specific behaviours based on their own beliefs about the behaviours and their expectations of a positive outcome after having engaged in the behaviours. The components of TPB directly affect his/her intention to complete behaviour and intention in turn influences whether an individual ultimately engages in the behaviour. Individuals' perception is in agreement with actual behavioural control. Ajzen (1991) suggested that perceived behavioral control serves a proxy for actual behavioural control, therefore having a direct influence on both intention and the actual behaviour. It can serve as a model to predict undergraduate students' engagement in unethical behaviours, specifically academic dishonesty (cheating, plagiarism, fraud, etc.). Moreover, it also serves as a model for the decision-making process used by students when forming the academic dishonesty intention and its subsequent behaviour. 


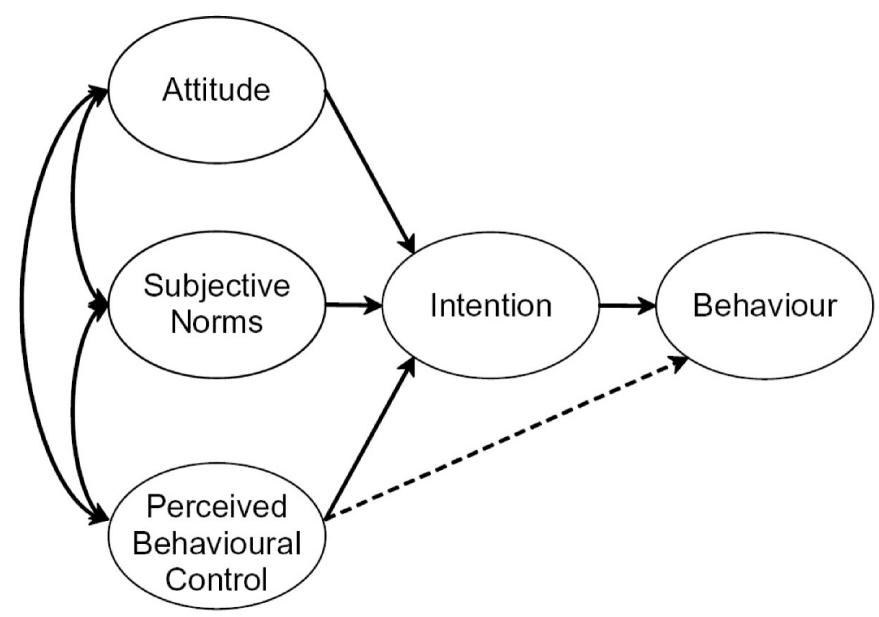

Figure 1. Theory of planned behavior (Ajzen, 1991)

\subsubsection{Intention}

Ajzen (1991) defined intention as an indication of how hard individuals are willing to try, how much of an effort they are planning to exert, in order to perform the behaviour. This component serves as an immediate precedent to the behaviour and is regarded as a central factor in the model of TPB as it captures the motivation for behaviour (Ajzen, 1991; Beck \& Ajzen, 1991). Ajzen (1991) proposed that the stronger a person's intention to engage in a behaviour, the greater the likelihood the particular behaviour will be elicited.

Beck and Ajzen (1991) concluded that intentions to engage in unethical behaviour are highly correlated with actual unethical behaviour, such as lying, cheating, shoplifting, etc. This is consistent with the study by Stone et al. (2007) which showed that significant intent may be more useful than behaviour as it generalises across situations such that cheating will occur when pressures to do so are high and barriers are low. This may help to explain why an individual who intends to cheat during an exam may carry out the said unethical behaviour in the exam hall.

\subsubsection{Attitude towards Behaviour}

Ajzen (1991) defined attitude as a disposition to respond favourably or unfavourably to an object, person, institution or event. Attitude is an individual's appraisal of how much he/she approves or disapproves of a specific behaviour. Beck and Ajzen (1991) further explained attitudes as the extent to which students condone or condemn academic dishonesty; they are more or less likely to form intentions to engage in cheating or plagiarism or other academic dishonesty as well as actually engage in behaviour.

Park and Blenkinsopp (2009) suggested that a person develops attitudes based on the beliefs he/she has about the behaviour under consideration by associating that behaviour with certain consequences. They acknowledged, however, that attitudes are a problematic measure, though many individuals have negative attitudes towards academic dishonesty (they think it is morally wrong and should not be attempted), yet most of them actually engage in this unethical behaviour when the times comes to do so. This is consistent with the study by Simon et al. (2003) which suggested that students with favourable attitudes toward academic integrity policies are more likely to report academic dishonesty than those who regard the policies as unfair.

\subsubsection{Subjective Norm}

This is the individual's perception that other individuals important to the respondent believe the respondent should perform the behaviour of interest (Ajzen, 1991). People are influenced by the behaviour of others, as noted by Stone et al. (2009). This influence can create a pressure to conform to the behaviour of members of a group, or may convey either what most people do in a given situation (i.e. descriptive norms) or behaviour that is associated with approval or sanctions (i.e. injunctive norm) by others (Stone et al., 2009). It is a normative expectation of other people regarding behaviour.

A norm is based on normative beliefs, which are a person's thoughts about the likelihood that important referent individuals or groups approve of their performing a given behaviour (Stone et al., 2009). It is represented by different normative beliefs and the motivation to meet the expectations of important others, such as family 
members, co-workers, immediate supervisors, friends or neighbours.

Whitley (1998) observed that the subjective norm has a considerable effect on cheating, such that students who perceive cheating is common are more likely to cheat than those who believe cheating is not common. This is consistent with the studies by McCabe et al. $(2002,2003)$, where students' perceptions of peers' behaviour was the best predictor of academic dishonesty regardless of the presence or absence of an honour code. In addition, perception that other students were cheating accounted for the greatest variance in cheating. The notion that social norms can outweigh behavioural prohibitions outlined in institutional policy as well as accepted ethical standards (McCabe et al., 2006).

\subsubsection{Perceived Behavioural Control}

Perceived behavioural control is added to TPB to enhance prediction in situations where behaviour may be constrained and / or violates norms or rules, such as academic integrity policies. Azjen (1991) defined it as the perceived ease of performing the behaviour based on past experiences and anticipated impediments. Ajzen (1991) suggested that when individuals perceive constraints on intended behaviours, perceived behavioural control could help to explain discrepancies between intentions and behaviour.

When attitudes and norms are strong, perceived behavioural control may have little effect on actual behaviours (Bunn et al., 1992; McCabe et al., 2002). When behaviours are perceived as challenging or there are barriers to performance, however, perceived behavioural control becomes a more important factor predicting behaviour, as suggested by McCabe et al. (2002). In McCabe et al. (2002), students' degree of certainty of being caught engaging in academic dishonesty predicted extent of dishonesty independent of an institution's policies regarding misconduct. Therefore, students have a greater propensity to engage in misconduct if sanctions are not imposed or are not severe enough to outweigh the potential benefits of cheating even when instructors and administrators warn students about the consequences of cheating.

Previous studies (Harding et al., 2007; Passow et al., 2006; Stone et al., 2007, 2009) indicate that several academic integrity researches have tested perceived behavioural control, and the results strongly indicated that the variable of perceived behavioural control is able to enhance the prediction where behaviour is not completely under a person's volitional control. Thus, perceived behavioural control takes into account whether a person has access to necessary resources and has the opportunity to engage in the behaviour, as also observed by Ajzen and Fishbein (1980). Academic dishonesty is an obvious example as it not only violates academic integrity policies but is also usually constrained by other factors, such as monitoring by exam invigilators and / or availability of test paper from an unauthorized source prior to taking it.

On the basis of the above review, TPB can be used as a model to explain how the three components (attitudes, subjective norm and perceived behavioural control), which are conceptually independent of each other, can influence an individual's intention to engage in academic dishonesty.

\subsection{Ethical Ideology}

In the studies conducted on unethical behaviour, fraud and academic dishonesty, ethical ideology has been recognised as one of the critical elements explaining the relationship (Chan et al., 2011; Forsyth, 1981b). Individuals who are acknowledged of wrongdoing by peer groups' members face ethical dilemma. They can face the wrongdoers directly and try to pursue them to alter their objectionable behaviour. Alternatively, they could simply put aside the unethical act and just walk away; or they could disclose the unethical behaviour to someone with higher authority to stop the activity (Forsyth, 1980).

Ethical ideology is termed an integrated system of ethics, which provides the guidelines for ethical judgments, ways to ethical dilemma and prescriptions for action in ethically dilemma situation (Chan et al., 2011; Forsyth, 1980). It contains the classifiable elements produced by previous experiences of handling ethical dilemmas (Chan et al., 2011). Lin and Ding (2003) further defined ethical ideology as the individual's approach to ethical judgment.

Forsyth (1980) suggested that ethical orientation consists of two different dimensions: idealism and relativism. The dimension of idealism measures the level where individual believes that desirable consequences can, with the right actions, always be obtained (Forsyth, 1980, p. 175). The dimension of relativism measures the degree to which an individual rejects universal moral rules as appropriate guidelines for ethical decisions (Forsyth, 1980, p. 175).

Forsyth (1980) brought the concepts of idealism and relativism together to produce a 2 x 2 taxonomy of ethical ideology. The matrix of ethical ideology is shown as the following Figure 2. 


\begin{tabular}{|c|c|c|}
\hline & \multicolumn{2}{|c|}{ Relativism } \\
\hline Idealism & High & Low \\
\hline High & $\begin{array}{c}\text { Situationist: } \\
\text { - Reject moral rules and review the } \\
\text { circumstances of a given situation to } \\
\text { determine the appropriate action }\end{array}$ & $\begin{array}{l}\text { Absolutist: } \\
\text { - Apply universal moral rules to achieve } \\
\text { the best possible outcome }\end{array}$ \\
\hline Low & $\begin{array}{c}\text { Subjectivist: } \\
\text { - Use personal value and opinion to } \\
\text { solve ethical issue raised }\end{array}$ & $\begin{array}{c}\text { Exceptionist: } \\
\text { - Apply moral judgment in pragmatic } \\
\text { way and are willing to accept } \\
\text { exceptions to these rules even if bad } \\
\text { consequences ensue }\end{array}$ \\
\hline
\end{tabular}

Figure 2. Forsyth's (1980) taxonomy of ethical ideologies

Forsyth (1980) acknowledged that high idealists believe that there is a morally correct alternative that will not harm others whereas high relativists will evaluate the current situation and use this as the basic for judgment. Those individuals who are low in idealism will make decisions irrespective of the impact on others. Forsyth (1980) also suggested, however, that low relativists tended to use universal moral rules to solve ethical issues in any event.

Forsyth et al.'s (1988) findings suggested that high-scoring idealism meant people espoused more altruistic ethical ideologies, which reflects a concern for the welfare of others, whereas a high score of relativism suggested that they would reject universal moral rules.

Idealists' ethical decisions are determined by undertaking the right action to produce good consequences, as suggested by Lin and Ding (2003). They also suggested that those low idealists will view the both good and bad consequences may ensue from an ethical decision, and that, under the circumstances, both are acceptable. As regards the dimension of relativism, Radtke (2004) suggested that the high relativist complies with a pre-determined moral protocol regardless of the consequences, whereas the low relativist pays no regard to the honour code but is guided in his / her ethical decision-making by the circumstances of the ethical dilemmas.

Past researchers (e.g. Barnett et al., 1994; Forsyth \& Nye, 1990; Lin \& Ding, 2003; Trevino, 2007) pointed to mixed results in their investigation of the relationship between ethical ideologies and ethical behaviours. Lin and Ding's (2003) findings indicated that ethical ideologies of students would diverge according to differences in their idealism and relativism scores. This is further supported by Trevino (2007), who concluded that ruthless individuals can be indifferent to ethical issues when seeking their personal goals.

Most of the previous studies (Barnett et al., 1994; Forsyth \& Nye, 1990; Lin \& Ding, 2003; Trevino, 2007) suggested that a relationship exists between ethical ideologies and academic misconduct. Cohen et al. (2001) suggested that the ethical behaviour of an individual with low relativism was worse than that of the individual with a high idealism score. This is consistent with the finding of Caswell and Gould (2008) that a strong relationship exists between an individual's ethical ideologies and his / her ethical behaviour, and a positive relationship exists between the intent to behave ethically and justice.

Singhapakdi et al. (1996) concluded that there was a significant relationship between idealism and ethical behaviour. This is consistent with the findings of Caswell and Gould (2008), who found a positive relationship within the dimensions of idealism and ethical behaviour, whereby respondents tended to be more sensitive as their idealism score increased.

As regards the dimension of relativism, Sparks and Hunt (1998) and Yetmar and Eastman (2000) suggested that there was a negative relationship between relativism and ethical behaviour. They suggested that ethical behaviour decreases as relativist orientation increases, hence causing unethical behaviour to increase. They concluded that absolutists were the most ethical whereas subjectivists were the least ethical. Absolutists tended to be stricter than both subjectivists and exceptionists. This is similar to Tansey et al. (1994), who also agreed that absolutists were the strictest in terms of their ethical behaviours, whereas subjectivists were the most lenient.

These results were inconsistent with Shaub et al. (1993), who pointed to a negative relationship between ethical ideologies and ethical behaviour. Their view was further strengthened by Chan and Leung (2006), who observed that there was a weak relationship between ethical ideologies and ethical behaviour. Emerson et al. (2007)'s 
findings showed, however, that there was a significant relationship between an individual's ethical ideologies and their ethical behaviour.

Ethical ideologies have been defined above as a set of personal moral beliefs with two different scales (idealism and relativism) which serve as guidelines for ethical behaviour and solutions when individuals face ethical dilemmas.

\subsection{Relationship between Theory of Planned Behaviour and Academic Dishonesty}

Several earlier studies (Baird, 1980; Drake, 1941; Hetherington \& Fledman, 1964; Jendreck, 1989; McCabe, 2005; Smyth \& Davis, 2004; Stone et al., 2007, 2009; Whitley, 1998) strongly indicated that the decline of academic integrity began some time ago and may be growing substantially. Many researchers (Beck and Ajzen, 1991; Harding et al., 2007; Stone et al., 2009; Whitley, 1998) suggested that theory-driven research is necessary to develop an understanding of the rationale underlying academic dishonesty and to determine the most effective means of curing this unethical behaviour. Furthermore, Stone et al. (2009) acknowledged that the components of TPB serve well to predict the actual behaviour rather than explain the behaviour expost.

In the study by Armitage and Conner (2001), TPB was found to account for 27 per cent and 39 per cents of the variance in behaviour and intention respectively. The findings also indicated that perceived behavioural control was particularly effective in that it accounted for significantly more variance in intention and behaviour beyond attitudes and subjective norms. Moreover, this finding was strengthened in the study by Symaco and Marcelo (2003), which concluded that there is a strong relationship between engagement in academic dishonesty behaviour and approval of such behaviour. Chang (1998) evaluated the influence of the three components of the theory on intention to behave unethically in the classroom using data from 181 graduate students. He found that TPB was an effective theoretical framework in predicting intention to commit unethical behaviour. This finding was further upheld by more recent studies (Buchan, 2005; Carpenter \& Reimers, 2005; McMillan \& Conner, 2003), where ТРВ was shown to be an effective theoretical framework for predicting intentions of ethical behaviour.

Bolin (2004) concluded that attitudes to cheating mediated the relationship between perceived opportunity and academic dishonesty and between self-control and academic dishonesty. Also, in McCabe et al. (2002) and Smyth and Davis (2004), the results significantly indicated that students acquired a subjective norm that cheating in college is common behaviour despite institutional policies that prohibit it. In addition, the finding is also consistent with the conclusions of Bunn et al. (1992), where students will have greater intention to engage in academic dishonesty if the punishment are not strong to scare off the students, even though the administrators had warn students about the consequences if they cheat.

\subsection{Relationship between Ethical Ideology and Theory of Planned Behaviour (TPB)}

Recently, few studies were carried out to explore the association between ethical ideology in academic dishonesty (Lin \& Ding, 2003; Trevino, 2007). Forsyth (1981b) believed that the sensitivity level of wrongdoing may vary among individuals with different ethical ideologies. He further suggested that differences in ethical ideology may affect the way in which individuals' process information about problems involving own or peer wrongdoing (Forsyth, 1985). This is supported by his later study (1999), which described association between ethical ideologies and positive viewpoints towards peer reporting in academic dishonesty as an appropriate response to unethical behavior. Moreover, several studies (Barnett et al., 1994; Forsyth, 1992) further acknowledged that individuals who differ in idealism and relativism approach ethical problems differently and often apply different approaches regarding the morality of particular behaviours.

In addition, Lin and Ding (2003) indicated that ethical judgments significantly influence the formation of behavioural intentions. Most models of ethical decision-making have found that individuals who judge an action to be highly ethical are more likely to form behavioural intention to perform that action (Ajzen, 1991; Hunt \& Vitell, 1986).

Forsyth and Nye's (1990) findings suggest that idealists are strongly concerned for the welfare of others, and hence they are likely to assess the possible damage unethical behaviour may cause to others, and to consider behaviour highly unethical if it has the potential to harm the entire organisation (Stone et al., 2010). Forsyth and Berger (1982) found that relativists believe that it is impossible to make accurate ethical judgments regarding the behaviour of others without knowing all the specific circumstances, and hence people are less likely to judge academic integrity harshly. Relativists are less likely to see that corrective behaviour of peer reporting is justified.

Forsyth and Nye (1990) acknowledged that idealists may also believe that academic integrity is an importance 
practice for safeguarding organisational interest against unethical wrongdoing, such as cheating in exams, plagiarising others' intellectual property, etc. The idealist believes that it is necessary to eschew any potential harmful action (cheating, plagiarism, etc.) to the institution and the community. This indicates that high idealists are highly sensitive to the welfare of others (school, community, organisation, etc.).

Non-relativists are less likely than relativists to violate a societal norm for personal gain (Lin \& Ding, 2003). This raises the possibility that relativists may be more inclined than non-relativists to engage in self-beneficial unethical behaviours, and are less likely to report such behaviour by peers. Consequently, relativism is positively linked with judging academic dishonesty as ethical, as suggested by Lin and Ding (2003).

\subsection{Proposed Conceptual Framework}

On the basis of the review of previous studies, the authors suggest a modified Theory of Planned Behaviour (Figure 2) with the components of ethical ideologies (idealism and relativism) for predicting and examining the relationship between the variables of academic dishonesty among undergraduates.

Findings strongly indicate that the Theory of Planned Behaviours is the most suitable tool for in-depth investigation of academic dishonesty. Only a few studies, however, have focused on the impact of ethical ideology in the model of Theory of Planned Behaviour. In the study by Lin and Ding (2003), results strongly suggested that the influence of ethical ideology is able to influence the formation of behavioural intention. Furthermore, they also acknowledged that differences in idealism and relativism may cause the individual to behave differently in handling ethical problems.

Ajzen (1991) suggested that most models of ethical decision-making found that individuals who judge an action as morally right are most likely to form behavioural intentions to carry out that action (Hunt \& Vitell, 1986). This view is further strengthened in the studies by Forsyth (1985) and Trevino (2007), where those individuals who scored higher in idealism tended to perceive academic dishonesty as unethical behaviour and would not compromise themselves by indulging in such behaviours; in contrast, high relativists tended to believe that sometimes academic dishonesty is necessary owing to the constraints of the environment and is not wrong. Barnett et al.'s (1996)'s findings also suggested that idealists tended to feel guilty if they engaged in academic dishonesty, and so they would not perform such behaviour, even though their peers engaged in it.

Forsyth (1999) acknowledged that the ethical ideologies and intention of individuals have a significant relationship, as individuals with a high idealism score tended to perceive peer reporting/whistleblowing as ethically right action, and also condemn those individuals who engage in academic dishonesty.

Through the review of past studies, it indicates that individual's personal moral philosophy and intention may interact. In order to gain a better score in assignment, a relativistic student may copy others' work to be as own work as he/she believe that personal gain from a good grade is more important that personal loss from cheating. This type of relativistic students may think that consequences of harming to others are lower. However, as an idealistic student, he/she may not do so, as he/she believe ethically right decision is more important compare cheat in assignment. This type of students may hold strongly on the consequences of harming, hence they will try to avoid involve such decision. From here, we can see that personal moral philosophy may serve as a mediating factor in influences students' intention to engage in academic dishonesty. Hence, following propositions are posited by the authors:

P1: There is a significant relationship between ethical ideologies of students and their intention to engage in academic dishonesty.

P2: There is a significant relationship between ethical ideologies of students and their behaviour in terms of academic dishonesty.

P3: There is a significant influence between intention and students cheating behavior with the mediating factor of personal moral philosophy.

On the basis of the above propositions, the authors propose the conceptual framework as illustrated in Figure 3. 


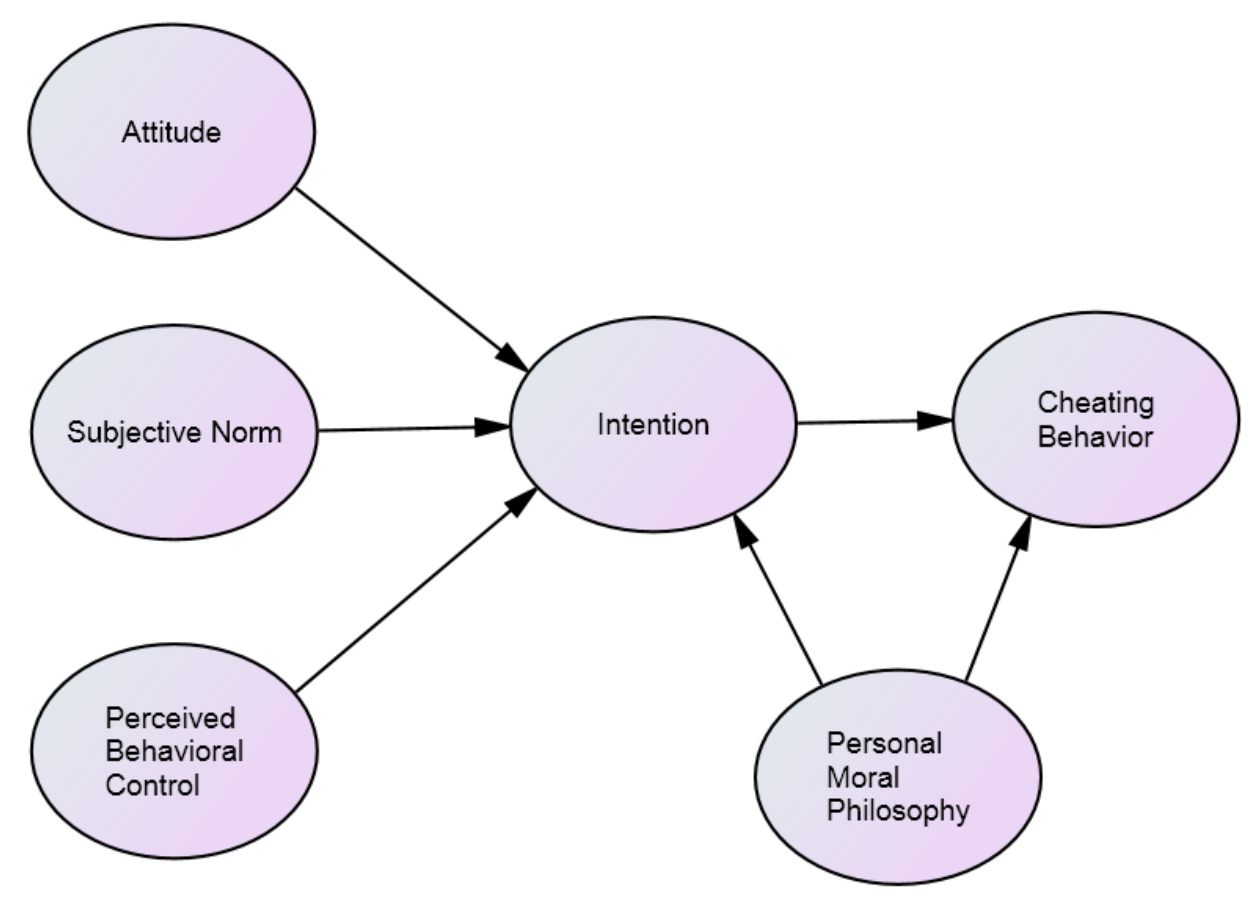

Figure 3. Modified theory of planned behaviour

\section{Conclusion}

Ethics is a science which concerns the question of right and wrong in human behaviour, a question of 'how things ought to be', as argued by Lillie (1971). Ethics begin with each individual's inner feelings, which subsequently transform into their behaviour. Shaw (2008) believes that every individual learns ethics during their upbringing, through socialising with others and the surrounding culture. Hence, this may explain the rationale of students who engage in academic dishonesty because of their beliefs about academic dishonesty and its consequences, the normative expectations of their peer groups and the ease or difficulty of carrying out such unethical behaviour.

Besides that, through this proposed framework, we can suggest that in order to develop good morality among students, lecturers and universities may help them to develop their ethical sensitivity through course syllabus, learning materials, code of ethical conduct etc. Furthermore, the universities also may organize several ethics-based workshop and conferences that compulsory for students to attend. These must ensure students are equipped with fundamental understanding and belief in business values, principles and ethics, apart from possessing an entrepreneurial spirit and the ability to access and manage risk. Hence, through this comprehensive ways of moral development, it may augment students' morality, which it will lead the students more ethical intention during their study time.

Kisamore et al. (2007) argued that most tertiary learning institutions aim to develop a culture of honesty through coherence to academic honor codes, universities ceremonies rituals and student pledges upon admission. It is crucial to deter academic dishonesty and to prevent rapidly happen deviant behavior. Academic dishonesty seems to be more frequently occurs when others are engaging in said behavior. Thus, it is important to make expectations clear, set high standards, demonstrate ethical behaviour, rewards students' ethical behaviour and punish students' unethical behaviour, all of which may be necessary to alter the attitudes, subjective norms and perceived behavioral control of students regarding academic dishonesty.

This paper has attempted to rebuild public confidence in academic integrity, dispel public mistrust of future undergraduates and bring about an insight of ethical issues among undergraduates in tertiary education institutions. It is also intended to encourage students to analysis the consequences and possible outcome of action from such ethical dilemmas for which guidelines, statutes or legal precedents do not exist.

Moreover, this paper argues for increased awareness that learning institutions have a responsibility to suggest 
with more capable solutions to foster integrity and alertly respond to academic dishonesty. The authors believe that besides the focuses on ethics education, like identifying unethical behavior and actions, academicians and universities also need to concern regards the unfairness and immorality of such unethical behaviour-in both academic and business settings.

Academia needs to be more attentive in its effort to curb academic dishonesty. We should not wait until individuals act unethically in organisations to deter, detect and punish them, such as the downfall of Enron whereby unethical behavior took a dreadful toll on the lives of countless people. Academicians should confront dishonesty, concern students fairly and encourage moral character development and the transfer of ethical knowledge. They should desist from declining students' morale and reducing public trust in the educational process.

The paper concludes that researchers need to develop a comprehensive theoretical framework in order to understand the underlying psychological mechanisms involved in students' ethical decision-making and behaviour and the influences of mediating variable - ethical ideology. Such empirical study may assist not only researchers but also educators to apply interventions effectively in promoting ethical decision-making and ethically right behaviours among graduates and undergraduates. Through this proposed framework, ethical ideology can help to reduce the increasing number of academic dishonesty through proper moral development from the university. Besides that, ethical ideology also proposed to intervened the unethical intention to engage in academic cheating, as students will have a different belief when they know about their wrong doing will bring the harms to others.

\section{References}

Ajzen, I. (1985). From intentions to actions: A theory of planned behavior. In J. Kuhl, \& J. Beckman (Eds.), Action-control: From cognition to behavior (pp. 11-39). Heidelberg: Springer. http://dx.doi.org/10.1007/978-3-642-69746-3_2

Ajzen, I. (1991). The theory of planned behavior. Organizational Behavior and Human Decision Processes, 50 , 179-211. http://dx.doi.org/10.1016/0749-5978(91)90020-T

Ajzen, I., \& Fishbein, M. (1980). Understanding Attitudes and Predicting Social Behavior. Englewood Cliffs, New Jersey: Prentice-Hall.

Arieff, S. R. et al. (2008). Persepsi Pelajar Universiti Teknologi Malaysia (UTM) terhadap Plagiarisme. Jurnal Teknologi, 48(E), 1-14.

Armitage, C., J., \& Conner, M. (2001). Efficacy of the theory of planned behavior: A meta analytic review. British Journal of Social Psychology, 40, 471-499. http://dx.doi.org/10.1348/014466601164939

Baird Jr., J. (1980). Current trends in college cheating. Psychology in the Schools, 17, 515-522. http://dx.doi.org/10.1002/1520-6807(198010)17:4<515::AID-PITS2310170417>3.0.CO;2-3

Barnett, T., Bass, K., \& Brown, G. (1994). Ethical ideology and ethical judgment regarding ethical issues in business. Journal of Business Ethics, 13(6), 469-480. http://dx.doi.org/10.1007/BF00881456

Barnett, T., Bass, K., \& Brown, G. (1996). Religiosity, ethical ideology and intentions to report a peer's wrongdoing. Journal of Business Ethics, 15(1), 1161-1174. http://dx.doi.org/10.1007/BF00412815

Beck, L., \& Ajzen, I. (1991). Predicting dishonesty actions using the theory of planned behavior. Journal of Research in Personality, 25, 285-301. http://dx.doi.org/10.1016/0092-6566(91)90021-H

Bolin, A. (2004). Self-control, perceived opportunity and attitudes as predictors of academic dishonesty. The Journal of Psychology, 138, 101-114. http://dx.doi.org/10.3200/JRLP.138.2.101-114

Brown, B. S., \& Chong, P. (2005). An investigation of academic dishonesty among business students at public and private United States universities. International Journal of Management, 22, 201-214.

Buchan, H. F. (2005). Ethical decision making in the public accounting profession: An extension of Ajzen's Theory of Planned Behavior. Journal of Business Ethics, 61, 165-181. http://dx.doi.org/10.1007/s10551-005-0277-2

Bunn, D. N., Caudill, S. B., \& Gropper, D. M. (1992). Crime in the classroom: An economic analysis of undergraduate student cheating behavior. Journal of Economic Education, 23(3), 197-207. http://dx.doi.org/10.2307/1183222

Carpenter, T. D., \& Reimers, J. L. (2005). Unethical and Fraudulent Financial Reporting: Applying the Theory of Planned Behavior. Journal of Business Ethics, 60, 115-129. 
http://dx.doi.org/10.1007/s10551-004-7370-9

Caswell, S. V., \& Gould, T. E. (2008). Individual moral philosophies and ethical decision making of undergraduate athletic training: A student and Educators. Journal of Athletic Training, 43(2), 205-214. $\mathrm{http}: / / \mathrm{dx}$.doi.org/10.4085/1062-6050-43.2.205

Chan, C. L. M., Othman, J., \& Jones, R. (2011). The Conceptual Model of Personal Moral Philosophy (PMP) and Ethical Decision Making (EDM). Journal of Management Research, 3(2). http://dx.doi.org/10.5296/jmr.v3i2.752

Chan, C. Y. S., \& Leung, P. (2006). The effects of accounting students' ethical reasoning and personal factors on their ethical sensitivity. Managerial Auditing Journal, 21(A), 436-457. http://dx.doi.org/10.1108/02686900610661432

Chang, M. K. (1998). Predicting unethical behavior: A comparison of the theory of Reasoned Action and the theory of Planned Behavior. Journal of Business Ethics, 17(16), 1825-1834. http://dx.doi.org/10.1023/A:1005721401993

Chapman, K. J., \& Lupton, R. A. (2004). Academic dishonesty in a global educational market: A comparison of Hong Kong and American university business students. International Journal of Educational Management, 18(7), 425-435. http://dx.doi.org/10.1108/09513540410563130

Chen, Y., \& Tang, T. (2006). Attitude toward and propensity to engage in unethical behavior: measurement invariance across major among university students. Journal of Business Ethics, 69, 77-93. http://dx.doi.org/10.1007/s10551-006-9069-6

Cohen, J. R., Pant, L. W., \& Sharp, D. J. (2001). An examination of differences in ethical decision making between Canadian Business Students and Accounting Professionals. Journal of Business Ethics, 30, 319-336. http://dx.doi.org/10.1023/A:1010745425675

Dichtl, J. (2003). Teaching Integrity. History Teacher, 36(3), 367. http://dx.doi.org/10.2307/1555693

Drake, C. A. (1941) Why students cheat? Journal of Higher Education, 12, 418-420. http://dx.doi.org/10.2307/1976003

Emerson, T., Conroy, S., \& Stanley, C. (2007). Ethical attitudes of accountants: Recent evidence from a practitioners' survey. Journal of Business Ethics, 71, 73-87. http://dx.doi.org/10.1007/s10551-006-9125-2

Farnsworth, J., \& Kleiner, B. H. (2003). Trends in Ethics Education at US Colleges and Universities. Management Research News, 26, 2. http://dx.doi.org/10.1108/01409170310783853

Finn, K. V., \& Frone, M. R. (2004). Academic performance and cheating: Moderating role of school identification and self-efficacy. The Journal of Educational Research, 97, 115-122. http://dx.doi.org/10.3200/JOER.97.3.115-121

Forsyth, D. R. (1980). A Taxonomy of Ethical Ideologies. Journal of Personality and Social Psychology, 39, 175-184. http://dx.doi.org/10.1037/0022-3514.39.1.175

Forsyth, D. R. (1981a). A psychological perspective on ethical uncertainties in behavioral research. In A. J. Kimmel (Ed.), New directions for methodology of social and behavioral science: Ethics of human subject research (Vol. 10). San Francisco: Jossey-Bass.

Forsyth, D. R. (1981b). Moral Judgment: The influence of ethical ideology. Personality and Social Psychology Bulletin, 7, 218-223. http://dx.doi.org/10.1177/014616728172006

Forsyth, D. R. (1985). Individual differences in information integration during moral judgment. Journal of Personality and Social Psychology, 49, 264-272. http://dx.doi.org/10.1037/0022-3514.49.1.264

Forsyth, D. R. (1999). Values, Conceptions of Science, and the Social Psychological Study of Morality. New York: Wiley.

Forsyth, D. R. (1992). Judging the morality of business practices: The influence of personal moral philosophies. Journal of Business Ethics, 11(5), 461-470. http://dx.doi.org/10.1007/BF00870557

Forsyth, D. R., \& Berger, R. E. (1982). The effects of ethical ideology on moral behavior. Journal of Social Psychology, 117, 53-56. http://dx.doi.org/10.1080/00224545.1982.9713406

Forsyth, D. R., \& Nye, J. L. (1990). Personal moral philosophies and moral choice. Journal of Research in Personality, 24, 398-414. http://dx.doi.org/10.1016/0092-6566(90)90030-A 
Forsyth, D. R., Nye, J. L., \& Kelly, K. (1988). Idealism, relativism and the ethics of caring. Journal of Psychology, 122, 243-248. http://dx.doi.org/10.1080/00223980.1988.9915511

Gehring, D., \& Pavela, G. (1994). Issues and perspectives on academic integrity. Washington, D.C.: National Association of Student Personnel Administrators.

Grimes, P. W. (2004). Dishonesty in academic and business: A cross-cultural evaluation of student attitudes. Journal of Business Ethics, 49(2), 273-290. http://dx.doi.org/10.1023/B:BUSI.0000017969.29461.30

Harding, T. S., Carpenter, D. D., Finelli, C. J., \& Passow, H. J. (2004). Does academic dishonesty relate to unethical behavior in professional practice? An explanatory study. Science and Engineering Ethics, 10(2), 311-326. http://dx.doi.org/10.1007/s11948-004-0027-3

Harding, T. S., Mayhew, M. J., Finelli, C. J., \& Carpenter, D. D. (2007). The Theory of Planned Behavior as a Model of Academic Dishonesty in Engineering and Humanities Undergraduates. Ethics and Behavior, 17(3), 255-279. http://dx.doi.org/10.1080/10508420701519239

Hetherington, M. E., \& Feldman, S. E. (1964). College cheating as a function of subject and situational variables. Journal of Educational Psychology, 55, 212-218. http://dx.doi.org/10.1037/h0045337

Hunt, S. D., \& Vitell, S. (1986). A General Theory of Marketing Ethics. Journal of Macromarketing Spring, 6(1), 5-16. http://dx.doi.org/10.1177/027614678600600103

Jendreck, M. P. (1989). Faculty reactions to academic dishonesty. Journal of College Student Development, 30, 401-406.

Karassavidou, E., \& Glaveli, N. (2006). Towards the ethical or the unethical side? An explorative research of Greek business students' attitudes. International Journal of Educational Management, 20, 348-364. http://dx.doi.org/10.1108/09513540610676421

Kisamore, J. L., Stone, T. H., \& Jawahar, I. M. (2007). Academic integrity: Individual and situational factors on academic conduct contemplation. Journal of Business Ethics, 75, 381-394. http://dx.doi.org/10.1007/s10551-006-9260-9

Lillie, W. (1971). An Introduction to Ethics (3rd ed.). London: Methuen \& Company Ltd.

Lin, C.-P., \& Ding, C. G. (2003). Ethical Ideology, Subjective Norm, and Peer Reporting Intentions using An Individual-Situation Moderator. Asia Pacific Management Review, 8(3), 311-335.

Lucas, G. M., \& Friedrich, J. (2005). Individual difference in workplace deviance and integrity as predictors of academic dishonesty. Ethics and Behavior, 15, 15-35. http://dx.doi.org/10.1207/s15327019eb1501_2

McCabe, D. I. (2005). Promoting academic integrity in business schools. Paper presented at the Professional Development Workshop, Academy of Management, Hawaii.

McCabe, D. I., Butterfield, K. D., \& Trevino, L. K. (2003). Faculty and academic integrity: The influence of current honor codes and past honor code experiences. Research in Higher Education, 44(3), 367-385. http://dx.doi.org/10.1023/A:1023033916853

McCabe, D. I., Butterfield, K. D., \& Trevino, L. K. (2006). Academic dishonesty in graduate business programs: Prevalence, Causes and Proposed Action. Academy of Management Learning and Education, 5(3), 294-305. http://dx.doi.org/10.5465/AMLE.2006.22697018

McCabe, D. I., Trevino, L. K., \& Butterfield, K. D. (2002). Honor codes and other contextual influences on academic integrity: A replication and extension of modified honor code settings. Research in Higher Education, 43, 357-378. http://dx.doi.org/10.1023/A:1014893102151

McCall, M. W. (1988). Developing executives through work experience. Human Resource Planning, 11(1), $1-12$.

McMillan, B., \& Conner, M. (2003). Applying an extended version of the Theory of Planned Behavior to illicit drug use among students. Journal of Applied Social Psychology, 33(8), 1662-1683. http://dx.doi.org/10.1111/j.1559-1816.2003.tb01968.x

Nonis, S., \& Swift, C. O. (2001). An examination of the relationship between academic dishonesty and workplace dishonesty: A multi-campus investigation. Journal of Educational for Business, 77(2), 69-77. http://dx.doi.org/10.1080/08832320109599052

Park, H., \& Blenkinsopp, J. (2009). Whistleblowing as Planned Behavior-A survey of South Korean Police Officers. Journal of Business Ethics, 85, 545-556. http://dx.doi.org/10.1007/s10551-008-9788-y 
Passow, H. J., Mayhew, M. J., Finelli, C. J., Harding, T. S., \& Carpenter, D. D. (2006). Factors influencing engineering students' decisions to cheat by type of assessment. Research in Higher Education, 47, 643-684. http://dx.doi.org/10.1007/s11162-006-9010-y

Petress, K. C. (2003). Academic Dishonesty: A plague on our profession. Education, 123(3), 624.

Roberts, E. (2002). Strategies for promoting academic integrity in CS course. 32nd Annual Frontiers in Education, 3. http://dx.doi.org/10.1109/FIE.2002.1158209

Shaub, M. K., Finn, D. W., \& Munter, P. (1993). The effects of auditors' ethical orientation on commitment and ethical sensitivity. Behavioral Research in Accounting, 5, 145-164.

Shaw, W. H. (2008). Business Ethics (6th ed.). Belmont, CA: Thompson Wadsworth.

Simon, C. A., Carr, J. R., McCullough, S. M., \& Oleson, T. R., M. (2003). The other side of academic dishonesty: The relationship between the faculty scepticism, gender and strategies for managing student academic dishonesty cases. Assessment and Evaluation in Higher Education, 28(2), 193. http://dx.doi.org/10.1080/02602930301669

Sims, R. R., \& Sims, S. J. (1991). Increasing applied business ethics. Journal of Business Ethics, 2, 211-219. http://dx.doi.org/10.1007/BF00383158

Singhapakdi, A., Vitell, S. J., Rallapalli K. C., \& Kraft, K. L. (1996). The perceived role of ethics and social responsibility: A scale development. Journal of Business Ethics, 15(11), 1131-1140. http://dx.doi.org/10.1007/BF00412812

Smyth, M. L., \& Davis, J. R. (2004). Perception of dishonesty among two years college students: Academic versus business situation. Journal of Business Ethics, 51(1), 63-73. http://dx.doi.org/10.1023/B:BUSI.0000032347.79241.3c

Sparks, J. R., \& Hunt, S. D. (1998). Marketing researcher ethical sensitivity: Conceptualization, measurement, and exploratory investigation. Journal of Marketing, 62(2), 92-109. http://dx.doi.org/10.2307/1252163

Staats, S., Hupp, J. M., Wallace, H., \& Gresley, J. (2009). Heroes don't cheat: An examination of academic dishonesty and students' views on why professors don't report cheating. Ethics and Behavior, 19(3), 171-183. http://dx.doi.org/10.1080/10508420802623716

Stone, T. H., Jawahar, I. M., \& Kisamore, J. L. (2009). Using the theory of Planned Behavior and Cheating justifications to predict academic misconduct. Career Development International, 14(3), 221-241. http://dx.doi.org/10.1108/13620430910966415

Stone, T. H., Jawahar, I. M., \& Kisamore, J. L. (2010). Predicting Academic Misconduct Intentions and Behaviors Using the Theory of Planned Behaviors and Personality. Basic and Applied Social Psychological, 32, 35-45. http://dx.doi.org/10.1080/01973530903539895

Stone, T. H., Kisamore, J. L., \& Jawahar, I. M. (2007). Predicting Academic Dishonesty. Paper presented at the 2007 Management Education Division of the Administrative Sciences Association of Canada, Ottawa, Ontario.

Symaco, L. P., \& Marcelo, E. (2003). Faculty perception on student academic honesty. College Student Journal, 37(3), 327-333.

Tansey, R. G., Brown, H., Hyman, M. R., \& Dawson Jr., L. E. (1994). Personal Moral Philosophies and the Moral Judgments of Salespeople. Journal of Personal Selling and Sales Management, 14(1), 59-75.

Trevino, L. K. (2007). The key role of HR in organizational ethics. Retrieved September, 2010, from http://www.ethics.org/erc-publications

Wang, Y., \& Kleiner, B. H. (2005). Defining Employee Dishonesty. Management Research News, 28(2/3), 11-22. http://dx.doi.org/10.1108/01409170510785057

Whitley, B. E. (1998). Factors associated with cheating among college students: A review. Research in Higher Education, 39(3), 235-274. http://dx.doi.org/10.1023/A:1018724900565

Yetmar, S. A., \& Eastman, K. K. (2000). Tax practitioners' ethical sensitivity: A model and empirical examination. Journal of Business Ethics, 26(4), 271-288. http://dx.doi.org/10.1023/A:1006294517573 


\section{Copyrights}

Copyright for this article is retained by the author(s), with first publication rights granted to the journal.

This is an open-access article distributed under the terms and conditions of the Creative Commons Attribution license (http://creativecommons.org/licenses/by/3.0/). 